\title{
Gait symmetry in the dual task condition as a predictor of future falls among independent older adults: a 2-year longitudinal study
}

\author{
Sophie Gillain ${ }^{1}$. Mohamed Boutaayamou ${ }^{2}$. Cedric Schwartz ${ }^{3}$. Nadia Dardenne ${ }^{3}$. Olivier Bruyère ${ }^{4}$ Olivier Brüls ${ }^{3}$. \\ Jean-Louis Croisier ${ }^{3,5}$. Eric Salmon ${ }^{6}$. Jean-Yves Reginster ${ }^{7} \cdot$ Gaëtan Garraux $^{3,6}$. Jean Petermans ${ }^{1}$
}

Received: 6 February 2019 / Accepted: 27 April 2019

(c) Springer Nature Switzerland AG 2019

\begin{abstract}
Background Given the potential consequences of falls among older adults, a major challenge is to identify people at risk before the first event. In this context, gait parameters have been suggested as markers of fall risk.

Aim To examine, among older people, the prospective relationship between gait patterns assessed in comfortable and challenging walking conditions, and future fall(s).

Method A total of 105 adults older than 65 years, living independently at home and without a recent fall history were included in a 2-year, longitudinal, observational study. All underwent physical and functional assessment. Gait speed, stride length, frequency, symmetry and regularity and Minimum Toe Clearance (MTC) were recorded in comfortable (CW), fast (FW) and dual task walking (DTW) conditions. Gait parameter changes occurring between CW and FW and between CW and DTW were calculated and expressed in percent. DTW cost was calculated as the change of DTW relative to CW. Fall events were recorded using fall diaries. Comparisons according to fall occurrence were performed by means of univariate analysis and multivariate binary logistic regression analysis.

Results Two-year follow-up was available for 96 participants, of whom 35 (36.5\%) fell at least once. Comparative analysis showed that future fallers had shorter FW stride length and higher symmetry DTW cost than non-fallers $(p<0.05)$. Binary logistic regression analysis showed that each additional percent of stride symmetry cost was associated with an increase in future fall risk (odds ratio 1.018, 95\% Confidence Interval (CI) 1.002-1.033; $p=0.027$ ).

Discussion Our results confirm the association between a symmetry decrease in DTW and future fall(s). Indeed in this study, the mean symmetry DTW cost in fallers is almost $20 \%$ higher than in non-fallers, meaning a fall risk that is around $36 \%$ higher than among non-fallers.

Conclusion This exploratory study shows the usefulness of considering gait parameters, particularly symmetry in challenging walking conditions, for early identification of future fallers.
\end{abstract}

Keywords Gait symmetry $\cdot$ Dual task $\cdot$ Fall risk $\cdot$ Older people $\cdot$ Prospective study

Electronic supplementary material The online version of this article (https://doi.org/10.1007/s40520-019-01210-w) contains supplementary material, which is available to authorized users.

Sophie Gillain

sgillain@chuliege.be

1 Geriatric Department, Liège University Hospital, C.H.U. site NDB, Route de Gaillarmont, 600, 4032 Chênée, Belgium

2 INTELSIG Laboratory, Department of Electrical Engineering and Computer Science, University of Liège, Liège, Belgium

3 Laboratory of Human Motion Analysis-LAMH, University of Liège, Liège, Belgium
4 Research Unit in Public Health, Epidemiology and Health Economics, University of Liege, Liège, Belgium

5 Science of Motricity Department, University of Liège, Liège, Belgium

6 Neurology Department and GIGA Cyclotron Research Centre, University of Liège, Liège, Belgium

7 WHO Collaborating Centre for Public Health Aspects of Musculoskeletal Health and Ageing, Liège, Belgium 


\section{Introduction}

Falls among older adults lead to injury, disability, functional decline [1], decreased quality of life [2], and a fear of falling, which is in turn linked with increased fall risk [3], and reduced social and physical activities $[4,5]$. Even in community-dwelling adults, the prevalence of falls is around $30 \%$ per year [6-8], reaching up to $43 \%$ per year in one longitudinal study [9].

The major challenge lies in discerning people at risk before the first fall occurs. In this context, a recent systematic review of the literature showed that, although prospective relationships remain to be confirmed by further longitudinal studies, gait parameters obtained using accelerometric methods can be considered as markers of fall risk [10]. Furthermore, tripping while walking seems to be one of the causes of falls in older adults living at home [11]. Accordingly, the risk of tripping is the combined result of the proximity of the swing foot to the ground, the high velocity of the swinging foot, and the forward-travelling center of mass being in front of the base of support [12-14]. Indeed, the minimum toe clearance (MTC), which is the local minimum distance between the ground and the toe of the forward swinging foot [15], could be considered as marker of trip risk [16]. However, to date, no study has assessed the prospective relationship between MTC values or variability, and the risk of future falls among older adults.

\section{Objective}

To examine, among older people, the prospective relationship between gait patterns assessed in comfortable and challenging walking conditions, and future fall(s).

\section{Methods}

We performed a two-year longitudinal, observational study. Volunteers were invited through a publicity campaign in national and local news media, or recruited during a public meeting focusing on healthy ageing. Inclusion criteria were: age at least 65 years, living independently at home, ability to understand French, and providing written informed consent. Exclusion criteria were: a history of fall(s) in the previous year, use of a walking aid, gait disorders and/or an increased fall risk related to neurological or osteoarticular disease (e.g. stroke, Parkinson's disease, lumbar spinal stenosis or polyneuropathy), dementia, hip or knee prosthesis in the previous year, pain when walking, acute respiratory or cardiac illness ( $<6$ months), recent hospitalization ( $<3$ months), untreated or uncontrolled comorbidities (e.g. hypertension, diabetes), use of neuroleptic and sedative drugs (use of sleeping pills was accepted) and presence of a cardiac pacing device (an exclusion criterion for the use of impedance).

At inclusion, all participants underwent medical history taking, clinical and functional assessment, and gait analysis. For all subjects, we recorded age, gender, level of education, current medications and alcohol and tobacco consumption. The burden of medical and surgical histories was scored by the Cumulative Illness Rating Scale geriatric version (CIRS-g) [17, 18]. Physical activity, exercise and sports habits were assessed by the Physical Activity Status Scale (PASS) [19, 20]. Acute or chronic pain perceived before walking tests was measured using a visual analogue pain scale [21]. Functional assessment included the activities of daily living (ADL) [22] and the instrumental activities of daily living (IADL) scales [23]. Considering that some housework is usually and preferentially done by the same member of the family, the IADL score was calculated as the sum of the scores obtained on the items applicable to each subject, divided by the sum of the maximum possible score on the applicable items [24].

Risk of mood disorders was assessed using the Geriatric Depression Scale short version (GDS-4) [25], and cognitive performance using the Montreal cognitive assessment (MoCA) [26]. Nutritional status was assessed using the Mini Nutritional Assessment short version (MNA-14) [26]. Frailty was assessed using two different tools, namely the Gérontopôle frailty screening tool (GFST) [27], and the Edmonton Frail Scale [28]. The fear of falling was assessed using the French version of the falls efficacy scale (FES-I) [29].

Clinical evaluation included a visual examination of spontaneous gait in order to exclude pain, limp or lateral motor deficit during gait. To assess and quantify any extrapyramidal stiffness, the examiner applied the unified Parkinson's disease rating scale criteria (UPDRS) [30]. Distance vision was tested using the French Monoyer's scale for $3 \mathrm{~m}$ [31]. Visual acuity less than 5/10 was reported as a visual impairment.

Anthropometric data assessment included the measure of body height, weight, waist circumference and hip circumference and the length of the right leg. The body mass index was calculated as the weight (in kilograms) divided by the height (in meters) squared. The skeletal muscle mass (SMM) was estimated based on bioelectrical impedance (BodyStat ${ }^{\circledR}$ 1500, Bodystat Ltd, Douglas, Isle of Man, UK) and using Janssen's validated estimating equation [32]. Furthermore, the skeletal muscle mass index (SMI) was calculated according to Janssen [33] and expressed in \%.

To assess overall muscle function, grip strength, muscle fatigue resistance (time in seconds when the contraction is over $50 \%$ of the maximal contraction force) and grip work (fatigue resistance $\times 75 \%$ of the maximal grip strength) of 
the dominant hand were assessed with a Martin's Vigorimeter used as per Bautmans [34].

Mobility and balance were assessed by the Timed Up and Go (TUG) test [35], the Functional Gait Assessment (FGA) [36] and the Short Physical Performance Battery (SPPB) [37].

The acquisition of gait parameters was based on two instrumental methods, namely an accelerometric method (Locometrix ${ }^{\circledR}$, Evry, France) and an opto electronic method (CodaMotion ${ }^{\circledR}$, Charnwood Dynamics Ltd, Rothley UK). The Locometrix ${ }^{\circledR}$ is a validated gait analysis system including a 3-D-acceleration sensor (inserted in an elastic belt placed in the lumbar position), a data logger and a computer program for processing the acceleration signals and calculating stride frequency, stride length, stride regularity and stride symmetry [38]. Stride symmetry describes the similarity of left and right cranial-caudal movements and is independent of fluctuations in the successive cranialcaudal movements of each limb. Stride regularity describes the similarity of vertical movements over successive strides. Symmetry and regularity are dimensionless. Details of the acquisition of gait parameters are given in supplementary data. The CodaMotion ${ }^{\circledR}$ system (Charnwood Dynamics, Rothley, UK) is a 3-dimensional kinematic tool based on an active optical system able to accurately measure the 3D position of active markers placed on the body on points of interest (e.g. ankle, knee, foot) and validated for use in laboratories [39, 40]. The use of position markers attached to the feet of the volunteers enables the application of the kinematic system to gait analysis while the 3-dimensional position and orientation of the feet are tracked using position cameras. Next, a signal-processing algorithm is applied to these recorded coordinates to extract the heel strike (HS) and toe-off (TO) timings for the right and left feet (Fig. 1). Further details are given in supplementary data. After processing and calculation, the MTC is expressed as the mean MTC value (Mean MTC), median MTC value (Med MTC), minimum MTC value (Min MTC), standard deviation of MTC value (SD MTC) and the coefficient of variation of MTC values (CoV MTC).

In order to standardize gait parameter acquisition, the organization of laboratory assessments was standardized as previously explained in [41].

Concerning the walking conditions, volunteers wore their own usual shoes with laces (used to attach the battery box to the shoes). Walking was recorded under three different experimental conditions: self-selected comfortable walking speed (CW), self-selected fast walking speed (FW) and during a dual-task walking condition (DTW) as previously explained in [41]. Furthermore, in order to assess the walking profile changes occurring between the comfortable walking condition and the dual task walking condition, the "DTW cost" was calculated for each gait parameter as follows: dual task cost parameter $=[(\mathrm{CW}$ gait parameter - DTW gait parameter)/CW gait parameter] $\times$ 100 (expressed in \%) where a "positive value" means a higher gait parameter value during CW than during DTW. Similarly, and in order to assess the walking profile changes occurring between the $\mathrm{CW}$ condition and the FW condition, we calculated "FW improvement" as follows: [(FW gait parameter $-\mathrm{CW}$ gait parameter $) / \mathrm{CW}$ gait parameter $] \times 100$ (expressed in \%), where a "positive value" means a higher gait parameter value during $\mathrm{FW}$ than during $\mathrm{CW}$.

At inclusion, all volunteers received a fall diary containing the aims of the study and the operational definition of fall. A fall was defined as an unexpected event in which the participant comes to rest on the ground, floor, or lower level [42]. To avoid fall underreporting, the volunteers were required to note every fall as soon as possible, detailing the circumstances in the fall diary. Every three months, each volunteer was contacted by phone to ask about fall(s) history. People who reported at least one fall during the follow-up period were considered as fallers.

Statistical analyses were performed using SAS version 9.4 (SAS Institute Inc., Cary, NC, USA) and MATLAB R2013a (Math Works, Natick, MA, USA). Quantitative parameters are expressed as mean \pm standard deviation (SD) or by median and interquartile range (Q1-Q3) for asymmetric distribution. Qualitative parameters are expressed as number (percentage). Normality was tested using the Shapiro-Wilk test and by investigating mean and median values, histograms and Quantile-Quantile plots. Homoscedasticity was tested using the Levenne test. Quantitative values were compared between groups by one-way analysis of Variance (ANOVA) or by the Kruskal-Wallis test depending on the normality of their distribution. The association between categorical variables was tested using the Chi square or Fisher's exact test as appropriate. As recommend by Armstrong [43], and considering that variables with a significant relation by univariate analysis were subsequently included in the logistic regression analysis, a $p$ value $<0.05$ after univariate comparison according to fall status was considered significant. Conversely, for the comparison between the subjects who completed follow-up and those who dropped out or were censored, a $p$ value $<0.001$ was considered significant.

The correlation between gait parameters and right leg length or within gait parameters was tested by Pearson's or Spearman's correlation coefficient according to the normality of their distribution. Normalization for right leg length was performed as "normalized parameter $=$ parameter/right leg length $(\mathrm{m})$ " for gait parameters correlated to the right leg length and showing significant differences according to fall incidence. In order to identify factors independently associated with the risk of fall, logistic regression was performed including the selected relevant variables. 


\section{Results}

One hundred and thirty-three volunteers were screened for eligibility between July 2014 and October 2015. Among these, one hundred and five subjects free of recent fall history and other exclusion criteria were included in the study. Two-year follow-up was available for 96 subjects (91.5\%). Indeed, nine volunteers were censored during follow-up: one died, one developed a neoplasm, one was diagnosed with dementia at inclusion, one was admitted to a nursing home; two volunteers did not leave the study but could not be contacted by telephone; two volunteers moved house and one person was excluded from follow-up because she fell due to a stroke. The comparison between those with complete followup and those who were censored found only one significant difference, namely for pain, with censored subjects reporting higher pain scores at inclusion $(2.28 \pm 2.43)$ than those who completed follow-up $(0.32 \pm 1.01), p$ value $<0.0001$. Other variables, especially thymic and cognitive scores, were not significantly different.

Among the 96 participants who were followed for 2 years, 48 were women and 48 were men; mean age was $71.3 \pm 5.4$ years (range $65-89$ years). The clinical and functional characteristics of the sample are shown in Table 1. Participants were well educated (the average duration of education was $13.03 \pm 3.55$ years), with low co-morbidities (mean CIRSg score $9.42 \pm 0.49$ ) and were taking few medications ( $71 \%$ were taking fewer than 5 drugs per day). Ninety-five per cent reported feeling well compared to people of similar age, and $90 \%$ were satisfied with their overall quality of life. Clinical assessment confirmed that the participants were independent in the activities of daily living (mean ADL score 6.21 \pm 0.41 ), not frail and performed the functional tests with satisfying results $(90 \%$ performed the Timed Up and Go test in less than $11 \mathrm{~s}$, mean FGA score $26.8 \pm 2.92$, mean SPPB score $10.41 \pm 1.57)$. Mean skeletal muscle index was $38.0 \pm 5.2$ in men and $33.3 \pm 5.2$ in women. Mean grip strength assessed with Martin's Vigorimeter was $72.4 \pm 16.1 \mathrm{kPa}$ in men and $51.9 \pm 15.9$ in women. Finally, mean gait speed was $1.29 \pm 0.18 \mathrm{~m} / \mathrm{s}$.

Concerning fall(s), among the 96 participants with complete follow-up, $35(36.4 \%)$ fell at least once during the follow-up period (18 men and 17 women, $p$ value $=0.83$ ). Age at inclusion did not differ between fallers [69 (67-76)] and non-fallers $[70(67-74)](p=0.94)$. There was no difference between groups in CIRSg total score with [9 (6-13)] in fallers and [9 (6-12)] in non-fallers $(p=0.82)$, or in the number of CIRSg items scored " 3 " or " 4 " with $[0(0-1)]$ in fallers and $[0(0-1)]$ in non-fallers. Tobacco consumption was not different between groups, with [0 (0-10)] pack-years reported in fallers, and $[0(0-18)]$ in non-fallers $(p=0.78)$. Five participants among the non-fallers $(8.2 \%)$ reported drinking at least 4 doses of alcohol per day compared to 4 among fallers $(11.4 \%)(p=0.72)$. Similarly, anamnestic data concerning self-reported quality of life found no significant differences between fallers and non-fallers. As shown in Table 1, fallers had significant higher stiffness $(p=0.043)$, lower IADL $(p=0.014)$ and SPPB scores $(p=0.015)$ than non-fallers. Figure 2 shows the box plot of these variables according to fall occurrence.

Concerning the comparison of gait performances according to fall(s) during follow-up, Table 2 shows that fallers had significantly lower gait speed in FW $(p=0.035)$, and shorter stride length in CW $(p=0.035)$ and in FW $(p=0.010)$. After normalization for the right leg length, FW gait speed and CW stride length were similar in both groups, whereas fallers have a "normalized" FW stride length significantly lower $(1.77 \pm 0.24)$ than non-fallers $(1.88 \pm 0.28)(p=0.046)$. Figure 3 shows the box plot of "normalized" FW stride length and the symmetry DTW cost. Table 3 shows that fallers had significantly higher symmetry DTW cost $(p=0.022)$ than non-fallers. As shown in the Table 4, MTC values were not different between the two groups. MTC changes in FW and in DTW were also not different between groups (data not shown).

As the number of events was reduced ( 35 fallers), the authors have to select four variables, among the five variables eligible. Considering the relationship between IADL scores and mobility are less intuitive, and considering the IADL score is correlated with the stiffness $(r=-0.37$, with $p$ value $<0.001$ ), the IADL score was not included in the binary logistic regression analysis. Thus symmetry DTW cost, FW stride length normalized to the leg length, stiffness and the SPPB score were selected to be included. Ninetythree observations (34 fallers and 59 non-fallers) were used for binary logistic regression analysis. Indeed, three observations were not used due to missing values (none were outliers) for explanatory variables. Missing values concerned a symmetry DTW cost value from one non-faller and stiffness values from one faller and one non-faller. The symmetry DTW cost (in percent) was shown to be significantly related to the risk of falls, with an odds ratio $(\mathrm{OR})=1.018$ (95\% confidence interval (CI) 1.002-1.033), $p$ value $=0.027$. Moreover, in order to not underestimate potential prospective relationship between IADL scores and fall(s), an additional binary regression analysis including IADL was realized which confirmed the symmetry DTW cost was the only variable with a prospective relationship with fall(s) (see additional analysis). 
Table 1 Clinical and functional characteristics according to fall status

\begin{tabular}{|c|c|c|c|}
\hline Variable & Fallers $(N=35)$ & Non-fallers $(N=61)$ & $P$ value \\
\hline $\operatorname{BMI}\left(\mathrm{kg} / \mathrm{m}^{2}\right)$ & $25.21 \pm 3.30$ & $26.19 \pm 3.83$ & 0.21 \\
\hline Skeletal Muscle Mass, SSM (kg) & $24.99 \pm 5.34$ & $27.02 \pm 5.63^{\mathrm{a}}$ & 0.095 \\
\hline Skeletal Muscle Index, SMI (\%) & $34.93 \pm 4.34$ & $36.26 \pm 5.62^{\mathrm{a}}$ & 0.25 \\
\hline Fatigue resistance (s.) & $45.93 \pm 31.71$ & $51.61 \pm 27.78$ & 0.27 \\
\hline Grip work $(\mathrm{kPa} \times \mathrm{s})$ & $2130.9 \pm 1650.3$ & $2529.8 \pm 1537.2^{\mathrm{b}}$ & 0.24 \\
\hline Right leg length $(\mathrm{cm})$ & $84(78-87)$ & $86(83-88)$ & 0.82 \\
\hline Pain score $(0-10)$ & $0(0-0)$ & $0(0-0)$ & 0.80 \\
\hline PAS score $(0-7)$ & $3(1-5)$ & $3(1-6)$ & 0.46 \\
\hline ADL (score/24) & $6(6-7)$ & $6(6-6)$ & 0.37 \\
\hline IADL (score/1) & $1(1-1)$ & $1(1-1)$ & 0.014 \\
\hline GDS (score/4) & $1(0-2)$ & $0(0-1)$ & 0.15 \\
\hline Covi (score/15) & $3(3-3)$ & $3(3-3)$ & 0.057 \\
\hline FES (score/64) & $19(17-20)$ & $18(17-20)$ & 0.073 \\
\hline MNA (score/14) & $13(12-14)$ & $14(12-14)$ & 0.36 \\
\hline Edmonton (/17) & $2(1-3)$ & $2(1-3)$ & 0.14 \\
\hline MoCA (score/30) & $27(26-29)$ & $28(26-29)$ & 0.62 \\
\hline Grip strength $(\mathrm{kPa})$ & $54(48-74)$ & $60(52-74)$ & 0.12 \\
\hline Grip work/Weight $(\mathrm{kPa} \times \mathrm{s} / \mathrm{kg})$ & $26.07(12.55-42.4)$ & $26.54(19.17-44.97)^{\mathrm{b}}$ & 0.21 \\
\hline Grip work/SMM $(\mathrm{kPa} \times \mathrm{s} / \mathrm{kg})$ & $76.90(41.13-116.76)$ & $74.90(55.38-126.43)^{\mathrm{b}}$ & 0.51 \\
\hline Grip work/SMI $(\mathrm{kPa} \times \mathrm{s} / \%)$ & $53.60(34.71-82.54)$ & $54.63(37.69-90.16)^{\mathrm{b}}$ & 0.46 \\
\hline Stiffness $(/ 15)$ & $0(0-2)^{d}$ & $\mathbf{0}(\mathbf{0}-\mathbf{0})^{\mathrm{b}}$ & 0.043 \\
\hline FGA (score/30) & $27(24-29)$ & $28(26-29)$ & 0.24 \\
\hline SPPB (score/12) & $10(9-11)$ & $11(10-12)$ & 0.015 \\
\hline
\end{tabular}

Data are presented as Mean \pm SD or Median (P25-P75) according to the normality of the distribution. Variables in bold are significantly different between groups

$B M I$ body mass index, $k P a$ kiloPascals, $P A S$ Physical Activity Status, $A D L$ activities of daily living, $I A D L$ instrumental activities of daily living, GDS Geriatric Depression Scale, CAS Covi anxiety score, FES Falls Efficacy Scale, MNA Mini Nutritional Assessment, MoCA Montreal Cognitive Assessment, FGA Functional Gait Assessment, SPPB Short Physical Performance Battery

${ }^{a} N=57$ due to 4 missing data

${ }^{\mathrm{b}} N=60$ due to 1 missing data

${ }^{\mathrm{c}} N=33$ due to 2 missing data

${ }^{\mathrm{d}} N=34$ due to 1 missing data

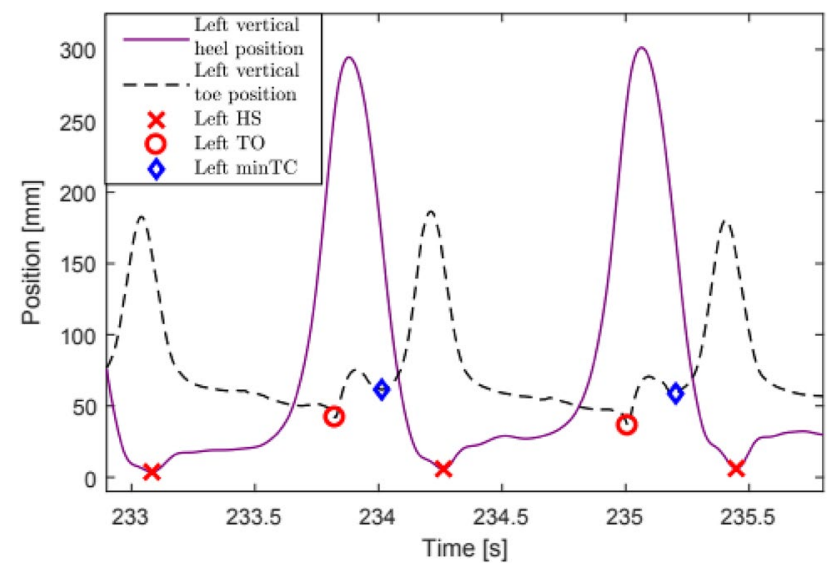

Fig. 1 Schematic representation of the position markers according to the time

\section{Discussion}

The main goal of this exploratory prospective study was to investigate whether, among healthy older adults, the assessment of gait patterns could be useful to discern people at risk of future fall(s). After 2 years of follow-up, one-third of the volunteers had fallen at least once. At inclusion, fallers had a significantly lower IADL score, lower SPPB score and higher stiffness as assessed by the UPDRS scale. In addition, after adjustment for the right leg length, fallers also had shorter FW normalized stride length and higher symmetry DTW cost than non-fallers. Logistic regression analysis showed that higher stride symmetry DTW cost was significantly associated with a higher fall risk.

In our study, over the 2 years of follow-up, $36 \%$ of participants experienced at least one fall. This rate is similar to previous studies involving older adults living at home, 


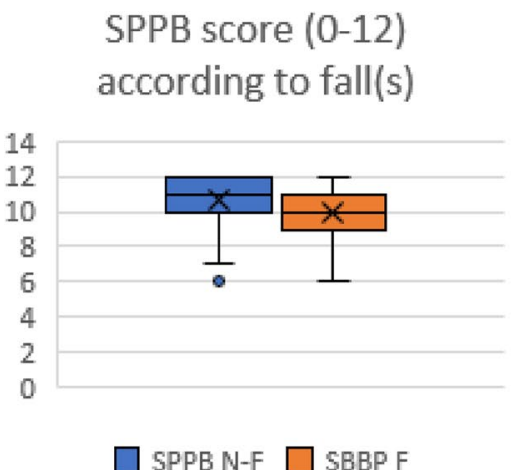

SPPB score (0-12)

SPPB N-F $\square$ SBBP F
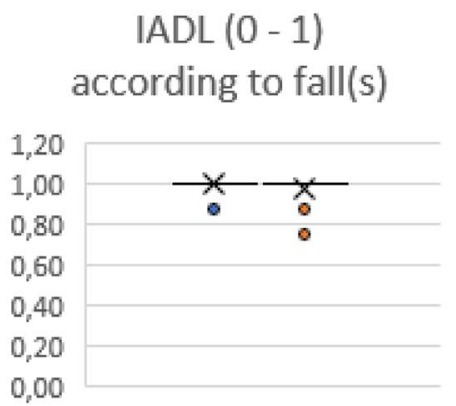

IADL N-F $\square$ IADL F
Stiffness (0 - 15) according to fall(s)

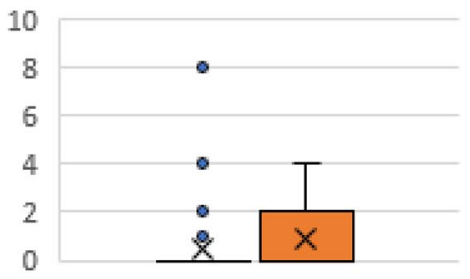

Stiffness N-F $\square$ Stiffness F

Fig. 2 Box Plots SPPB, IADL and Stiffness according to fall(s)

Table 2 Comparison of gait parameters obtained using the accelerometric method according to fall status
Fig. 3 Box Plot of FW Normalized Stride Length and Symmetry DTW Cost according to fall(s)

\begin{tabular}{lccc}
\hline Variable & Fallers $(N=35)$ & Non-fallers $(N=61)$ & $P$ value \\
\hline CW gait speed (m/s) & $1.24 \pm 0.18$ & $1.31 \pm 0.18$ & 0.078 \\
FW gait speed (m/s) & $\mathbf{1 . 6 4} \pm \mathbf{0 . 2 4}$ & $\mathbf{1 . 7 4} \pm \mathbf{0 . 2 2}$ & $\mathbf{0 . 0 3 5}$ \\
DTW gait speed (m/s) & $1.16 \pm 0.19$ & $1.17 \pm 0.24^{\mathrm{a}}$ & 0.86 \\
CW stride length (m) & $\mathbf{1 . 3 0} \pm \mathbf{0 . 1 7}$ & $\mathbf{1 . 3 7} \pm \mathbf{0 . 1 5}$ & $\mathbf{0 . 0 3 5}$ \\
FW stride length (m) & $\mathbf{1 . 4 7} \pm \mathbf{0 . 2 3}$ & $\mathbf{1 . 6 0} \pm \mathbf{0 . 2 4}$ & $\mathbf{0 . 0 1 0}$ \\
DTW stride length (m) & $1.26 \pm 0.18$ & $1.31 \pm 0.28^{\mathrm{a}}$ & 0.31 \\
CW stride frequency (Stride/s) & $0.96 \pm 0.08$ & $0.96 \pm 0.07$ & 0.91 \\
FW stride frequency (Stride/s) & $1.10 \pm 0.08$ & $1.08 \pm 0.11$ & 0.39 \\
CW regularity (dimensionless) & $301.80 \pm 48.29$ & $305.28 \pm 46.98$ & 0.73 \\
FW regularity (dimensionless) & $299.86 \pm 56.55$ & $311.33 \pm 51.87$ & 0.32 \\
DTW regularity (dimensionless) & $263.69 \pm 59.85$ & $248.80 \pm 63.71^{\mathrm{b}}$ & 0.27 \\
FW symmetry (dimensionless) & $205.69 \pm 51.37$ & $218.34 \pm 54.51$ & 0.27 \\
DTW stride frequency (Stride/s) & $0.93(0.88-1.03)$ & $0.93(0.83-0.96)^{\mathrm{a}}$ & 0.14 \\
DTW symmetry (dimensionless) & $197(162-223)$ & $208(170-275.5)^{\mathrm{a}}$ & 0.11 \\
\hline
\end{tabular}

Mean \pm SD or Median (P25-P75) were showed depending of the normality of the variable's distribution. Variables in bold are significantly different between groups

$C W$ comfortable walking, $m$ meters, $s$ second, $F W$ fast walking, $D T W$ dual task walking

${ }^{\mathrm{a}} N=60$ due to one missing data

${ }^{\mathrm{b}} N=59$ due to 2 missing data

\section{FW Normalized Stride Length according to fall(s) (m)}

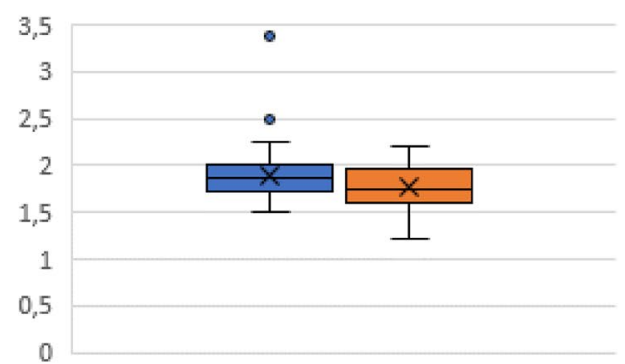

FW Normalized Stride Length $N-F$

FW Normalized Stride Length $\mathrm{F}$
Symmetry DTW Cost according to fall(s) (\%)

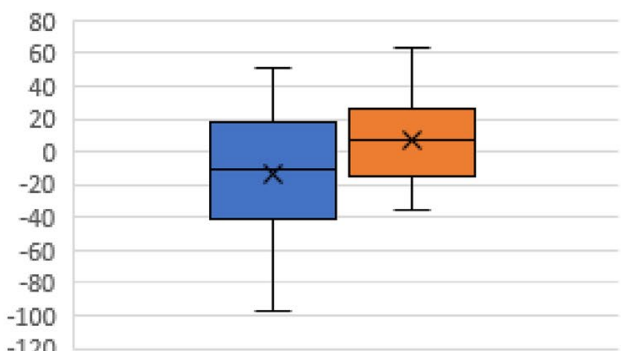

Symmetry DTW Cost N-F

Symmetry DTW Cost F 
Table 3 Comparison of FW and DTW changes of gait parameters according to fall status

Table 4 MTC values according to fall status

\begin{tabular}{|c|c|c|c|}
\hline Variable & Fallers $(N=35)$ & Non-fallers $(N=61)$ & $P$ value \\
\hline Gait speed FW improvement (\%) & $32.20 \pm 13.68$ & $33.21 \pm 10.91$ & 0.69 \\
\hline Stride length DTW cost (\%) & $2.94 \pm 7.00$ & $5.87 \pm 18.56$ & 0.37 \\
\hline Stride length FW improvement (\%) & $13.39 \pm 7.96$ & $17.36 \pm 14.20$ & 0.13 \\
\hline Regularity DTW cost (\%) & $12.64 \pm 14.16$ & $21.01 \pm 22.70$ & 0.052 \\
\hline Regularity FW improvement (\%) & $-0.37 \pm 13.14$ & $2.67 \pm 13.89$ & 0.29 \\
\hline Gait speed DTW cost $(\%)$ & $6.90(0.83-13.55)$ & $8.45(2.43-18.85)^{\mathrm{a}}$ & 0.14 \\
\hline Stride frequency DTW cost (\%) & $4.85(0.00-8.04)$ & $5.24(0.00-10.20)^{\mathrm{a}}$ & 0.11 \\
\hline Stride frequency FW improvement (\%) & $14.29(9.18-20.43)$ & $15.05(10.75-18.45)$ & 0.93 \\
\hline Symmetry DTW cost (\%) & $7.32(-15.42$ to 26.07$)$ & $-11.83(-41.56 \text { to } 18.44)^{\mathrm{a}}$ & 0.022 \\
\hline Symmetry FW improvement (\%) & $-6.63(-20.79$ to 16.78$)$ & $10.21(-8.76$ to 32.11$)$ & 0.059 \\
\hline
\end{tabular}

Mean \pm SD or Median (P25-P75) were showed depending of the normality of the variable's distribution. Variables in bold are significantly different between groups

$F W$ fast walking, $D T W$ dual task walking

${ }^{\mathrm{a}} N=60$ due to 1 missing data

\begin{tabular}{llll}
\hline Variable & Fallers $(N=33)$ & Non-fallers $(N=55)$ & $P$ value \\
\hline CW Mean MTC $(\mathrm{mm})$ & $17.32 \pm 5.66$ & $17.76 \pm 5.16$ & 0.71 \\
DTW Mean MTC $(\mathrm{mm})$ & $15.01 \pm 5.65^{\mathrm{b}}$ & $15.31 \pm 5.50^{\mathrm{a}}$ & 0.82 \\
CW Med MTC $(\mathrm{mm})$ & $17.35 \pm 5.85$ & $17.70 \pm 5.20$ & 0.77 \\
FW Med MTC $(\mathrm{mm})$ & $18.72 \pm 6.18^{\mathrm{b}}$ & $20.78 \pm 7.35^{\mathrm{a}}$ & 0.18 \\
DTW Med MTC $(\mathrm{mm})$ & $14.77 \pm 5.80^{\mathrm{b}}$ & $15.27 \pm 5.58^{\mathrm{a}}$ & 0.70 \\
DTW Min MTC $(\mathrm{mm})$ & $13.65 \pm 6.77^{\mathrm{b}}$ & $14.15 \pm 7.37^{\mathrm{a}}$ & 0.76 \\
FW Mean MTC $(\mathrm{mm})$ & $17.98(14.78-22.93)^{\mathrm{b}}$ & $20.61(16.21-24.14)^{\mathrm{a}}$ & 0.35 \\
CW SD MTC $(\mathrm{mm})$ & $4.99(3.32-5.35)$ & $4.12(2.83-5.42)$ & 0.21 \\
FW SD MTC $(\mathrm{mm})$ & $4.46(3.37-7.07)^{\mathrm{b}}$ & $4.52(3.21-6.47)^{\mathrm{a}}$ & 0.74 \\
DTW SD MTC $(\mathrm{mm})$ & $3.59(2.68-6.13)^{\mathrm{b}}$ & $4.12(2.72-5.20)^{\mathrm{a}}$ & 0.77 \\
CW CoV MTC $(\%)$ & $27.00(20.13-34.07)$ & $24.33(17.17-30.94)$ & 0.16 \\
FW CoV MTC $(\%)$ & $26.14(16.79-39.19)^{\mathrm{b}}$ & $27.59(18.23-35.00)^{\mathrm{a}}$ & 0.90 \\
DTW CoV MTC $(\%)$ & $27.10(12.84-35.59)^{\mathrm{b}}$ & $24.92(15.05-38.67)$ & 0.98 \\
CW Min MTC $(\mathrm{mm})$ & $10.75(8.36-14.48)$ & $11.97(9.31-16.09)$ & 0.24 \\
FW Min MTC $(\mathrm{mm})$ & $9.88(6.93-12.20)^{\mathrm{b}}$ & $9.13(6.88-11.69)^{\mathrm{a}}$ & 0.87 \\
\hline
\end{tabular}

Mean \pm SD or Median (P25-P75) were showed depending of the normality of the variable's distribution. Variables in bold are significantly different between groups

$C W$ comfortable walking, MTC minimum toe clearance, $F W$ fast walking, $D T W$ dual task walking, Med median, Min minimum, $S D$ standard deviation, $C o V$ coefficient of variation

${ }^{\text {a }} N=54$ due to one missing data

${ }^{\mathrm{b}} N=30$ due to 3 missing data which reported a fall rate of $38 \%$ after a mean follow-up period of 20 months [44] or a fall rate of $25.6 \%$ after a 1 -year follow-up period [45]. However, other prospective studies have shown that fall rates among similar samples can vary widely. Indeed, one study reported a fall incidence of $15 \%$ per year (although the authors underlined that follow-up was not sufficient to ensure complete fall event collection) [46], whereas another prospective study reported a fall incidence of $45 \%$ over a one-year follow-up period [47], and the characteristics of the participants included in both studies were quite similar. These different results support the idea that, even in similar participants and using the same definition of the negative outcome, the variation in fall rates is probably related to different methods of recording fall events, different levels or types of physical activity, and different daily life environments, which were not taken into account in these studies or in the present study.

In terms of clinical characteristics and functional performances, fallers and non-fallers were similar in our study, except for IADL score, SPPB score and stiffness based on 
the UPDRS scale. However, even though the difference reached statistical significance $(p<0.05)$, the differences between fallers and non-fallers were not clinically relevant in this cohort. Indeed, although the mean and standard deviation between groups differed, the box plots show that a wide range of values could match a non-faller as much as a faller (Fig. 3). Then, according our results, IADL, SPPB and the stiffness according the UPDRS scale appear not useful to identify future fullers among independent older adults without recent fall history.

Concerning the relationship between gait parameters recorded at inclusion and fall(s) events during the followup, after adjustment for right leg length, fallers had a shorter normalized FW stride length and a higher symmetry DT cost than non-fallers.

Focusing on the prospective relationship between FW stride length and future fall(s), our results are similar to those obtained among the TASCOG study, a 1-year followup study involving 176 adults aged $60-86$ years, living at home, without walking aids and non-demented and assessing assessed FW step length and their changes in CW and FW expressed in percentage [47]. The TASCOG study found that FW step length (expressed in $\mathrm{cm}$ ) was significantly associated with the risk of experiencing multiple falls (RR 0.95; 95\% CI 0.89-0.99). The step length change (between CW and $\mathrm{FW}$ ) was not associated with occurrence of a single fall. Further comparison with the TASCOG study is limited by the non-availability of data concerning multiple falls in our sample.

The prospective relationship between symmetry DTW cost and future fall(s) is suggested by comparison analysis and confirmed by binary logistic regression analysis, which showed that symmetry DTW cost was significantly associated with a higher risk of fall within the two following years. Indeed, for every $1 \%$ increase in symmetry DTW cost, the fall risk increased by $1.8 \%$. In our population, the mean symmetry DTW cost of fallers was almost $20 \%$ higher than that of non-fallers, meaning that future fallers had a fall risk that was around $36 \%$ higher than those who were non-fallers. This opens perspectives for identifying patients who might benefit from fall prevention measures.

A French 2-year longitudinal study focusing on fall risk and using the same accelerometric method (Locometrix ${ }^{\circledR}$ ) also showed that stride symmetry was associated with future fall(s) along with other gait parameters [48]. Furthermore, if we assume that stride symmetry assesses a similar gait component to step regularity, then our results are in line with Bautmans et al. who compared gait patterns of 40 older adults who had a high fall risk (mean age $80.6 \pm 5.4$ years) with those of 41 non-faller older adults (mean age $79.1 \pm 4.9$ years) and found that older adults at risk of falls had less step regularity than non-fallers [49]. In addition, in a 1-year cohort study including 319 community-dwelling older adults (mean age $75.5 \pm 6.9$ ), gait symmetry, assessed as harmonic ratio measured in three axes and in daily-life walking conditions, was found to have a negative relationship with future fall risk [50]. Finally, the prospective relationship between gait symmetry measures and prospective fall(s) are also confirmed among post-stroke patients followed for fall(s) during one year [51].

Actually, in our opinion, these results support the idea the stride symmetry is linked to the automatic stepping activity coming from central pattern generators (CPGs) as previously suggested and summarized [52]. The hypothesis according to which gait symmetry is not related to cortical influences is also supported by the review of Morris et al. showing the absence of evidence linking cognitive functions and gait symmetry [53]. In our sample, the DTW, which reduces the attentional resources allocated to gait, thereby reducing the cortical influences on gait performance, probably enabled an increase CPGs activity, leading to a stride symmetry increase.

Although our results need to be confirmed in a larger sample, they are encouraging and support the hypothesis that gait parameters could be used as early markers of fall risk among older adults not "known" to be at risk. Indeed, in this study, the CW and DTW stride symmetry values were obtained in less than 5 min using a very easy-to-use mobile tool available outside gait laboratory. Applied to clinical practice, the systematic measure of gait symmetry in CW and DTW could help to earlier identify older adults at risk of future falls, and enable early proactive, evidence-based interventions aimed at reducing falls and their consequences.

Furthermore, our results open new avenues for further research opportunities. First, it seems important to confirm our findings in a larger sample and to define a cut-off value identifying people at risk for falls based on symmetry DTW cost. Next, intervention studies should assess whether improving gait symmetry in DTW would potentially reduce the fall risk. Finally, technical progress could be harnessed to enable measurement of this parameter as quickly and easily as possible during standardized gait recordings available not only in clinical practice, but also in daily life conditions.

The main strengths of this study include the well-documented sample. To the best of our knowledge, this is the first study to include independent older people without a fall history, screened using comprehensive clinical and functional assessments, and with gait analysis recording six gait parameters in three different walking conditions. Initial phone contact, anamnesis, clinical exam and functional evaluation guarantee the absence of subjects who presented exclusion criteria. Furthermore, anamnestic, clinical and functional data obtained at inclusion made it possible to discuss the gait patterns obtained and their relationship with future fall(s).

Moreover, the use of three different walking conditions and the calculation of the gait changes occurring between 
$\mathrm{CW}$ and $\mathrm{FW}$ (i.e. gait parameter $\mathrm{FW}$ improvement) or between CW and DTW (i.e. gait parameter DTW cost) is one of the originalities of this experimental research. To the best of our knowledge, this study is the first to show so many gait parameters in three walking conditions and their changes according to the walking condition. Moreover, systematic randomization of the FW and DTW rules out any fatigue effect that could be due to performance of the same walking condition.

This study also has some limitations that deserve to be underlined. First, the sample size is small. Thus, the absence of significant relationships between some gait parameters and future falls does not mean that no such relationships exist. Furthermore, a larger sample would make it possible to observe a higher number of falls, to include higher number of variables in logistic regression analysis and confer additional robustness on the multivariate analysis. Finally, concerning the sample size, a further potential criticism could be the lack of a priori power calculation in order to define the sample size. The main reason for this is that there is a paucity of available comparisons concerning the MTC (thus precluding calculation of a sample size). Nevertheless, except for the study by Mignardot et al. including 259 older adults [48], the few available studies focusing on accelerometric data in research into fall risk included similar sample sizes: 46 volunteers in the study of Marschollek et al. [56]., 73 volunteers in the study of Doi et al. [57] and 100 volunteers in the study of Mansfield et al. [51].

Second, this study did not take into account the number of falls (i.e. no difference was made between people who fell once and those who fell several times), the fall consequences, or the context in which the fall occurred (e.g. at home, in the street, on snow, in a dual task situation, in more complex situations, during challenging physical activity, tripping, slipping or losing balance). Finally, this study did not take into account the cognitive performance during the dual task walking condition. Further studies should consider measure this parameter to investigate whether fallers give more priority to the cognitive task during DTW or not.

\section{Conclusions}

Our results support the idea that gait pattern assessment could be useful to detect, among healthy older adults, those at risk of future falls, especially the symmetry DTW cost, which was found to be independently associated with future fall risk. However MTC values in CW and in challenging walking conditions did not appear useful to identify future fallers. Although our results warrant confirmation in a larger sample, they open interesting avenues for further systematic gait pattern records in clinical practice and for interventional studies aimed at investigating whether an improvement in gait symmetry would reduce the fall risk.

Acknowledgements The authors would like to thank Mrs. Sophie Christelbach (MD) and Mrs. Celine Ricour (PhD) for their help for the recruitment, Mrs. Vinciane Wojtasik for the follow-up and Mrs. Fiona Ecarnot (EA3920, University Hospital Besancon, France) for her editorial support.

Funding This study was supported by a grant from the Belgian fund for scientific research (F.N.R.S.).

\section{Compliance with ethical standards}

Conflict of interest On behalf of all authors, the corresponding author states that there is no conflict of interest.

Ethical approval All procedures performed in studies involving human participants were in accordance with the ethical standards of the institutional and/or national research committee and with the 1964 Helsinki declaration and its later amendments or comparable ethical standards.

Informed consent All participants provided informed consent prior their participation.

\section{References}

1. Rubenstein LZ (2006) Falls in older people: epidemiology, risk factors and strategies for prevention. Age Ageing 35:ii37-ii41. https://doi.org/10.1093/ageing/afl084

2. Thiem U, Klaaßen-Mielke R, Trampisch U, Moschny A, Pientka L, Hinrichs T (2014) Falls and EQ-5D rated quality of life in community-dwelling seniors with concurrent chronic diseases: a cross-sectional study. Health Qual Life Outcomes 12:2. https:// doi.org/10.1186/1477-7525-12-2

3. Scheffer AC, Schuurmans MJ, van Dijk N, van der Hooft T, de Rooij SE (2008) Fear of falling: measurement strategy, prevalence, risk factors and consequences among older persons. Age Ageing 37:19-24. https://doi.org/10.1093/ageing/afm169

4. Delbaere K, Crombez G, Vanderstraeten G, Willems T, Cambier D (2004) Fear-related avoidance of activities, falls and physical frailty. A prospective community-based cohort study. Age Ageing 33:368-373. https://doi.org/10.1093/ageing/afh106

5. Choi K, Ko Y (2015) Characteristics associated with fear of falling and activity restriction in south korean older adults. J Aging Health 27:1066-1083. https://doi.org/10.1177/089826431557351 9

6. Tinetti ME, Speechley M, Ginter SF (1988) Risk Factors for Falls among Elderly Persons Living in the Community. N Engl J Med 319:1701-1707. https://doi.org/10.1056/nejm198812293192604

7. Craig J, Murray A, Mitchell S, Clark L, Saunders L, Burleigh L (2013) The high cost to health and social care of managing falls in older adults living in the community in Scotland. Scott Med J 58:198-203

8. Morrison A, Fan T, Sen SS, Weisenfluh L (2013) Epidemiology of falls and osteoporotic fractures: a systematic review. Clinicoecon Outcomes Res 5:9-18. https://doi.org/10.2147/ceor.s38721

9. Delbaere K, Close JCT, Brodaty H, Sachdev P, Lord SR (2010) Determinants of disparities between perceived and physiological risk of falling among elderly people: cohort study. BMJ 341:c4165. https://doi.org/10.1136/bmj.c4165 
10. Gillain $S$, Boutaayamou $M$, Beaudart $C$, Demonceau $M$, Bruyère O, Reginster JY, Garraux G, Petermans J (2018) Assessing gait parameters with accelerometer-based methods to identify older adults at risk of falls: a systematic review. Eur Geriatr Med 1-14. https://doi.org/10.1007/s41999-018-0061-3

11. Blake AJ, Bendall KMMJ, Dallosso H, Ebrahim SB, Arie TH, Fentem PH, Bassey EJ (1988) Falls by elderly people at home: prevalence and associated factors. Age Ageing 17:365-372

12. Winter (1992) Foot trajectory in human gait: a precise and multifactorial motor control task. Phys Ther 72:45-53

13. Mills PM, Barrett RS (2001) Swing phase mechanics of healthy young and elderly men. Hum Mov Sci 20:427-446. https://doi. org/10.1016/S0167-9457(01)00061-6

14. Barrett RS, Mills PM, Begg RK (2010) A systematic review of the effect of ageing and falls history on minimum foot clearance characteristics during level walking. Gait Posture 32:429-435. https://doi.org/10.1016/j.gaitpost.2010.07.010

15. Alan RDA, John GB (2015) The effects of walking speed on minimum toe clearance and on the temporal relationship between minimum clearance and peak swing-foot velocity in unilateral trans-tibial amputees. Prosthet Orthot Int 39:120-125. https://doi. org/10.1177/0309364613515493

16. Schulz BW, Lloyd JD, Lee WE (2010) The effects of everyday concurrent tasks on overground minimum toe clearance and gait parameters. Gait Posture 32:18-22. https://doi.org/10.1016/j.gaitp ost.2010.02.013

17. Linn BS, Linn MW, Gurel LEE (1968) Cumulative Illness Rating Scale. J Am Geriatr Soc 16:622-626. https://doi. org/10.1111/j.1532-5415.1968.tb02103.x

18. Miller MD, Paradis CF, Houck PR, Mazumdar S, Stack JA, Rifai AH, Mulsant B, Reynolds CF (1992) Rating chronic medical illness burden in geropsychiatric practice and research: application of the Cumulative Illness Rating Scale. Psychiatry Res 41:237248. https://doi.org/10.1016/0165-1781(92)90005-N

19. Jackson ASBS, Mahar MT, Wier LT, Ross RM, Stuteville JE (1990) Prediction of functional aerobic capacity without exercise testing. Med Sci Sports Exerc 22:863-870

20. Jackson AS, Ross RM (1996) Methods and limitations of assessing functional work capacity objectively. J Back Musculoskelet Rehabil 6:265-276. https://doi.org/10.3233/bmr-1996-6307

21. Hawker GA, Mian S, Kendzerska T, French M (2011) Measures of adult pain: visual Analog Scale for Pain (VAS Pain), Numeric Rating Scale for Pain (NRS Pain), McGill Pain Questionnaire (MPQ), Short-Form McGill Pain Questionnaire (SF-MPQ), Chronic Pain Grade Scale (CPGS), Short Form-36 Bodily Pain Scale (SF-36 BPS), and Measure of Intermittent and Constant Osteoarthritis Pain (ICOAP). Arthr Care Res 63:S240-S252. https://doi.org/10.1002/acr.20543

22. Katz S, Ford AB, Moskowitz RW, Jackson BA, Jaffe MW (1963) Studies of illness in the aged: the index of adl: a standardized measure of biological and psychosocial function. JAMA 185:914-919. https://doi.org/10.1001/jama.1963.0306012002 4016

23. Lawton MPBE (1969) Assessment of older people: self-maintaining and instrumental activities of daily living. Gerontologist 9:179-186

24. Gillain S, Warzee E, Lekeu F, Wojtasik V, Maquet D, Croisier J-L, Salmon E, Petermans J (2009) The value of instrumental gait analysis in elderly healthy, MCI or Alzheimer's disease subjects and a comparison with other clinical tests used in single and dualtask conditions. Ann Phys Rehabil Med 52:453-474. https://doi. org/10.1016/j.rehab.2008.10.004

25. D'Ath P, Katona P, Mullan E, Evans S, Katona C (1994) Screening, detection and management of depression in elderly primary care attenders. I: the acceptability and performance of the 15 item Geriatric Depression Scale (GDS15) and the Development of Short Versions. Fam Pract 11:260-266

26. Nasreddine ZS, Phillips NA, Bédirian V, Charbonneau S, Whitehead V, Collin I, Cummings JL, Chertkow H (2005) The montreal cognitive assessment, MoCA: a brief screening tool for mild cognitive impairment. J Am Geriatr Soc 53:695-699. https://doi.org /10.1111/j.1532-5415.2005.53221.x

27. Vellas B, Balardy L, Gillette-Guyonnet S, Abellan Van Kan G, Ghisolfi-Marque A, Subra J, Bismuth S, Oustric S, Cesari M (2013) Looking for Frailty in Community-dwelling Older Persons: the Gérontopôle Frailty Screening Tool (GFST). The Journal of Nutrition, Health \& Aging 17:629-631. https://doi.org/10.1007/ s12603-013-0363-6

28. Rolfson DB, Tsuyuki RT, Tahir A, Rockwood K (2006) Validity and reliability of the Edmonton Frail Scale. Age and Aging 35:526-529

29. Delbaere K, Close JCT, Mikolaizak AS, Sachdev PS, Brodaty H, Lord SR (2010) The Falls Efficacy Scale International (FESI). A comprehensive longitudinal validation study. Age Ageing 39:210-216. https://doi.org/10.1093/ageing/afp225

30. Goetz CG, Tilley BC, Shaftman SR, Stebbins GT, Fahn S, Martinez-Martin P, Poewe W, Sampaio C, Stern MB, Dodel R, Dubois B, Holloway R, Jankovic J, Kulisevsky J, Lang AE, Lees A, Leurgans S, LeWitt PA, Nyenhuis D, Olanow CW, Rascol O, Schrag A, Teresi JA, van Hilten JJ, LaPelle N (2008) Movement Disorder Society-sponsored revision of the Unified Parkinson's Disease Rating Scale (MDS-UPDRS): scale presentation and clinimetric testing results. Mov Disord 23:2129-2170. https:// doi.org/10.1002/mds. 22340

31. Casellato L (1994) New developments in visual acuity charts. Ophthalmologica 208:95-97

32. Janssen I, Heymsfield SB, Baumgartner RN, Ross R (2000) Estimation of skeletal muscle mass by bioelectrical impedance analysis. J Appl Physiol 89:465-471

33. Janssen I, Heymsfield SB, Ross R (2002) Low relative skeletal muscle mass (Sarcopenia) in older persons is associated with functional impairment and physical disability. J Am Geriatr Soc 50:889-896. https://doi.org/10.1046/j.1532-5415.2002.50216.x

34. Bautmans IM (2005) A fatigue resistance test for elderly persons based on grip strength: reliability and comparison with healthy young subjects. Aging Clin Exp Res 17:217-222

35. Podsiadlo D, Richardson S (1991) The timed "up and go"; A test of basic functional mobility for frail elderly persons. J Am Geriatr Soc 39:142-148. https://doi.org/10.1111/j.1532-5415.1991.tb016 16.x

36. Wrisley DM, Marchetti GF, Kuharsky DK, Whitney SL (2004) Reliability, internal consistency, and validity of data obtained with the functional gait assessment. Phys Ther 84:906-918

37. Guralnik JM, Simonsick EM, Ferrucci L, Glynn RJ, Berkman LF, Blazer DG, Scherr PA, Wallace RB (1994) A short physical performance battery assessing lower extremity function: association with self-reported disability and prediction of mortality and nursing home admission. J Gerontol 49:M85-M94

38. Auvinet B, Berrut G, Touzard C, Moutel L, Collet N, Chaleil D, Barrey E (2002) Reference data for normal subjects obtained with an accelerometric device. Gait Posture 16:124-134. https://doi. org/10.1016/s0966-6362(01)00203-x

39. Gortoniii GE, Hebert DA, Gannotti ME (2008) Assessment of the kinematic variability among 12 motion analysis laboratories. Gait Posture 29:398-402. https://doi.org/10.1016/j.gaitp ost.2008.10.060

40. Schwartz C, Denoël V, Forthomme B, Croisier J-L, Brüls O (2015) Merging multi-camera data to reduce motion analysis instrumental errors using Kalman filters. Comput Methods Biomech Biomed Eng 18:952-960. https://doi.org/10.1080/10255842.2013.864640 
41. Gillain S, Boutaayamou M, Dardenne N, Schwartz C, Demonceau M, Gerontitis C, Depierreux F, Salmon E, Garraux G, Bruyère O, Brüls O, Croisier J-L, Petermans J (2017) Data set of healthy old people assessed for three walking conditions using accelerometric and opto-electronic methods. Aging Clin Exp Res 29:1201-1209. https://doi.org/10.1007/s40520-017-0730-y

42. Lamb SE, Jørstad-Stein EC, Hauer K, Becker C, on behalf of the Prevention of Falls Network E, Outcomes Consensus G (2005) Development of a common outcome data set for fall injury prevention trials: the prevention of falls network europe consensus. J Am Geriatr Soc 53:1618-1622. https://doi.org/10.111 1/j.1532-5415.2005.53455.x

43. Armstrong RA (2014) When to use the Bonferroni correction. Ophthalmic Physiol Opt 34:502-508. https://doi.org/10.1111/ opo. 12131

44. Verghese J, Holtzer R, Lipton RB, Wang C (2009) Quantitative gait markers and incident fall risk in older adults. J Gerontol A Biol Sci Med Sci 64A:896-901. https://doi.org/10.1093/gerona/ glp033

45. Srygley JM, Herman T, Giladi N, Hausdorff JM (2009) Selfreport of missteps in older adults: a valid proxy of fall risk? Arch Phys Med Rehabil 90:786-792. https://doi.org/10.1016/j. apmr.2008.11.007

46. Laessoe U, Hoeck HC, Simonsen O, Sinkjaer T, Voigt M (2007) Fall risk in an active elderly population — can it be assessed? J Negative Results BioMed 6:2. https://doi.org/10.1186/1477-5751-6-2

47. Callisaya ML, Blizzard L, McGinley JL, Srikanth VK (2012) Risk of falls in older people during fast-walking - the TASCOG study. Gait Posture 36:510-515. https://doi.org/10.1016/j.gaitp ost.2012.05.003

48. Mignardot JB, Deschamps T, Barrey E, Auvinet B, Berrut G, Cornu C, Constans T, de Decker L (2014) Gait disturbances as specific predictive markers of the first fall onset in elderly people: a two-year prospective observational study. Front Aging Neurosci 6:22. https://doi.org/10.3389/fnagi.2014.00022

49. Bautmans I, Jansen B, Van Keymolen B, Mets T (2011) Reliability and clinical correlates of 3D-accelerometry based gait analysis outcomes according to age and fall-risk. Gait Posture 33:366-372. https://doi.org/10.1016/j.gaitpost.2010.12.003

50. van Schooten KS, Pijnappels M, Rispens SM, Elders PJM, Lips P, Daffertshofer A, Beek PJ, van Dieën JH (2016) Daily-life gait quality as predictor of falls in older people: a 1-year prospective cohort study. PLoS One 11:e0158623. https://doi.org/10.1371/ journal.pone.0158623

51. Mansfield A, Mochizuki G, Inness EL, McIlroy WE (2012) Clinical correlates of between-limb synchronization of standing balance control and falls during inpatient stroke rehabilitation. Neurorehabil Neural Repair 26:627-635. https://doi. org/10.1177/1545968311429688

52. Yogev G, Plotnik M, Peretz C, Giladi N, Hausdorff JM (2007) Gait asymmetry in patients with Parkinson's disease and elderly fallers: when does the bilateral coordination of gait require attention? Exp Brain Res 177:336-346. https://doi.org/10.1007/s0022 1-006-0676-3

53. Morris R, Lord S, Bunce J, Burn D, Rochester L (2016) Gait and cognition: mapping the global and discrete relationships in ageing and neurodegenerative disease. Neurosci Biobehav Rev 64:326-345. https://doi.org/10.1016/j.neubiorev.2016.02.012

54. Ebersbach G, Dimitrijevic MR, Poewe W (1995) Influence of concurrent tasks on gait: a dual-task approach. Percept Mot Skills 81:107-113. https://doi.org/10.2466/pms.1995.81.1.107

55. Beauchet O, Allali G, Poujol L, Barthelemy JC, Roche F, Annweiler C (2010) Decrease in gait variability while counting backward: a marker of "magnet effect"? J Neural Transm 117:11711176. https://doi.org/10.1007/s00702-010-0463-y

56. Marschollek M, Rehwald A, Wolf K-H, Gietzelt M, Nemitz G, Schwabedissen ZU, Schulze HM (2011) Sensors vs. expertsa performance comparison of sensor-based fall risk assessment vs. conventional assessment in a sample of geriatric patients. BMC Med Inform Decis Mak 11:48-49. https://doi. org/10.1186/1472-6947-11-48

57. Doi T, Hirata S, Ono R, Tsutsumimoto K, Misu S, Ando H (2013) The harmonic ratio of trunk acceleration predicts falling among older people: results of a 1-year prospective study. J Neuroeng Rehabil 10:7-76. https://doi.org/10.1186/1743-0003-10-7

Publisher's Note Springer Nature remains neutral with regard to jurisdictional claims in published maps and institutional affiliations. 